\title{
DISCIPLINA NA EDUCAÇÃO \\ INFANTIL? UM OLHAR SOBRE O \\ ESPAÇO FÍSICO E O \\ DISCIPLINAMENTO DA CRIANÇA. ${ }^{1}$
}

\author{
Alexandra Fátima Lopes de Souza ${ }^{2}$ \\ Dorcas Tussi ${ }^{3}$ \\ Ireno Antonio Berticelli ${ }^{4}$
}

Nesse texto, discutir-se-á sobre alguns aspectos relevantes na organização do espaço no atendimento às crianças na Educação Infantil, bem como a produção do disciplinamento. Para tanto, objetivou-se investigar a organização do espaço educativo e, a partir disso, compreender as estratégias de disciplinamento da criança presentes na instituição de educação infantil. Para clarificar este estudo, recorreuse ao levantamento bibliográfico, de cunho qualitativo-fenomenológico, realizamos a pesquisa de campo em uma instituição, de Chapecó-SC. De alguma forma, o espaço escolar é organizado de acordo com o pensamento moderno de espaço fixo. Além disso, as salas de aula da pré-escola apresentam marcas "escolarizantes" na sua organização, e quando organizadas em espaços funcionais com o controle do tempo, propicia o disciplinamento da criança.

Palavras-chave: Educação infantil. Organização do espaço. Disciplinamento. 


\section{Situando o estudo}

As novas pesquisas 1 relativas ao espaço, tempo, gênero, culturas infantis, brincar, entre outras, iniciaram-se há pouco tempo, precisamente, na década de 1990 (ROCHA, 1999a). Assim, torna-se necessário desvendar novas proposições neste debate, bem como a emergência da análise de novas categorias de investigação do universo infantil com vistas à consolidação de uma pedagogia da infância. Por isso, a nossa proposta foi pesquisar a organização do espaço físico e o disciplinamento da criança2 na educação infantil de Chapecó/SC. Algo nos inquietava e surpreendia: "criam-se espaços" de educação para atender a infância, mas há a necessidade de se estudar que espaços são esses, para que eles existem e como são organizados. Além disso, verificamos que é moderna a criação do infantil e também recente sua inclusão no sistema de ensino nacional.

A educação infantil teve respaldo, no Brasil, com a Constituição de 1988, em que prevê creches e pré-escolas às crianças de zero a seis anos em lugares específicos e formais de ensino, e foi sistematizada na LDB Lei de Diretrizes e Bases da Educação Nacional n. ${ }^{\circ}$ 9394/96. Em seu artigo 29, a LDB comenta que a educação infantil é a primeira etapa da educação básica e “(...) tem como finalidade o desenvolvimento integral da criança até seis anos de idade, em seus aspectos físico, psicológico, intelectual e social, complementando a ação da família e da comunidade". Nesse sentido, compreende-se o porquê de poucos estudos sobre o espaço educativo e se concebe o quão atual é discutir a organização do espaço em que acontece a educação para a infância.

Os espaços e tempos modernos constituíram-se pelas intensas mudanças na organização social, política e econômica da sociedade. A disciplina, por sua vez, atua de modo, muitas vezes, imperceptível na forma como se organizam os espaços e tempos para a infância na Educação Infantil; como em lugares cerceados, com divisórias ou não, e no tempo delimitado rigorosamente para cada atividade. Brincar na sala, brincar no parque, lanchar, educação física, atividade, assistir vídeo, muitas vezes, são atividades impostas pelo professor sem considerar a importância de ouvir as crianças e suas manifestações de interesses e participação na organização do tempo e espaço da sala de aula. As crianças desde pequenas, ao adentrar o universo escolar, começam a incorporar regras, 
disciplinas, rotinas e, muitas vezes, ao conflitarem-se com tais imposições são vistas como sem limites ou indisciplinada.

Considerando estas análises, visamos à compreensão da educação, da sociedade sob "novos olhares"; olhares estes que façam a análise sobre o disciplinamento e o poder disciplinar; entendendo que essas categorias estão presentes no meio social e, principalmente, na escola e na educação em si, atuando sobre a criança de modo peculiar, às vezes, imperceptível. Erguer a mão para falar, não falar alto, obedecer ao sinal de entrada, de recreio e saída, todos constituem estratégias de disciplinamento que são incorporados pela criança desde cedo. Por isso, indagamos: como está organizado o espaço físico da educação infantil e como ele produz o disciplinamento da criança? Investigamos, então, as características do espaço educativo, sua organização para, a partir disso, ter a compreensão das estratégias de disciplinamento sobre a criança.

O referencial teórico foi tomado de Michel Foucault, e as análises basearam-se em uma abordagem qualitativa da realidade que não poderia ser quantificada, uma vez que trabalhamos com uma gama de significados, motivos, aspirações, crenças, valores e atitudes. Como pesquisadoras, nos aprofundamos nos significados das ações e relações humanas, algo que não pode ser quantificado (MINAYO, 1999, p. 21 - 22).

A partir do estudo foucaultiano, evidenciamos o pensar, o espaço, e o disciplinamento da criança sob a ótica fenomenológica, a qual parte do diálogo dos fenômenos com a ciência, em nosso caso, os fenômenos que ocorrem no espaço da educação infantil, sem objetivações. A soma dessas questões resultou na busca por ocorrências cotidianas que pudessem nos auxiliar na compreensão da relação entre organização do espaço e disciplina.

A abordagem fenomenológica esteve presente no trabalho de maneira bem simples. Investigamos e observamos cada atividade realizada com as crianças como um fenômeno. A hora do lanche, a hora da atividade, o recreio, ou seja, nas mais diversas textualidades do espaço educativo, pudemos compreender que o disciplinamento da criança era produzido através de múltiplas estratégias, práticas, táticas e "tecnologias" particulares. Cada atividade foi minuciosamente observada e, como num grande quebracabeça, cada uma se tornou uma peça fundamental de análise. 


\section{Refletindo sobre a infância}

É a vulnerabilidade infantil que autoriza nossas práticas e ações sobre as crianças. Não é difícil associar o nosso poder e o nosso saber às ações empreendidas sobre elas, pois, por sua fragilidade e dependência, não encontram qualquer obstáculo e oposição. Por que algo mais trivial do que o nascimento de uma criança? É algo extremamente habitual. Portanto, o “(...) nascimento nada mais é (...) do que o princípio de um processo no qual a criança começa a estar no mundo e começa a ser um de nós” (LARROSA, 1998, p. 71-72).

As crianças, esses seres estranhos dos quais nada se sabe, esses seres selvagens que não entendem nossa língua. No entanto, podemos abrir um livro de psicologia infantil e saberemos de suas satisfações, de seus medos, de suas peculiares maneiras de sentir e de pensar. Podemos ler um estudo sociológico e saberemos de seu desamparo, da violência que se exerce sobre elas, de seu abandono, de sua miséria. (LARROSA, 1998, p. 67).

Larrosa (Ibid.) procurou expor que, por este ponto de vista, a criança não passa de "objeto". Objeto de estudos “(...) de um conjunto de saberes mais ou menos científicos". Por assim dizer, o autor também explica que a criança “(...) é algo que nossos saberes, nossas práticas e nossas instituições já capturaram”, pois, explica-se, nomeia-se, interfere-se e acolhe-se; tudo isso é feito em relação a elas. Logo, nosso campo de ação sobre as crianças está posto à medida que todas essas questões são colocadas (LARROSA, Ibid., p. 68). Essas questões conduzem facilmente ao tema "educação". Pensar sobre: acolher, interferir e explicar à criança implica pensar sobre educação e ao modo pelo qual os adultos passaram a entendê-la em cada momento histórico. Podemos, aqui, referir-nos ao questionamento proposto pelo autor (Ibid., p. 73): o que significa para a educação o fato de que nasçam seres humanos no mundo? O que significa que a educação seja justamente uma relação com a infância entendida simplesmente como aquele que nasce? A esse questionamento o autor responde de forma enfática e segura que a educação é o modo como as pessoas, 
as instituições, e as sociedades respondem à chegada dos que nascem e também a forma como o mundo os recebem. A recepção e a resposta aos que nascem representam a presença marcante do adulto no mundo infantil e a sua interferência sobre ele.

Desse modo, Larrosa (Ibid.) expõe que responder e receber aos que nascem significa assumir uma responsabilidade e “(...) abrir um espaço no qual aquele que vem possa habitar”(p.73). Porém, não significa reduzir a infância à “(...) algo que de antemão já sabemos o que é, o que quer ou de que necessita"(p.73). Analisa-se a utilização de conceitos e explicações a priori sobre a educação da criança pequena, que nada mais representam do que o que os adultos pensam sobre ela.

É a partir deste momento que, ao pensar na educação das crianças, começa-se a conceber "(...) a escola como lugar privilegiado, ou seja, o lugar em que o aprender e o ensinar ocorrem de maneira correta" (BERTICELLI, 1998, p. 14), neste sentido o autor (Ibid.) chama a escola de lugar do saber. É desta forma que a escola moderna foi entendida, como um lugar perfeito e absoluto para o saber e para a passagem deste às crianças. Percebemos até aqui que, ao receber as crianças, os adultos (inclusive a pedagoga/professora) agem de acordo com a concepção de infância que tem. Isso significa que há um conhecimento "pronto" sobre ela e ignora-se o "outro" presente na infância, sendo esse "outro" o que está sempre além do pensamento pré-definido dela e acerca dela. Aqui se pode mais uma vez dialogar com a ideia de Larrosa (1998), a criança é tratada pela nossa prática e saberes como algo já apreendido. O próprio processo de condução do(a) aluno(a)/criança pelo(a) pedagogo(a) já supõe um privilégio da escola como "lugar do saber" e como indicador de uma concepção de infância e/ou pedagógica.

Berticelli (1998) explica que todas as reformas do ensino ocorridas ao longo da história foram

(...) realizadas ao molde das reformas religiosas históricas, onde se interpõem sempre novas determinações dogmáticas que devem garantir coisas impossíveis de garantir, coisas sem as quais os cidadãos aparentemente não poderiam sobreviver, como por 
exemplo, os percentuais de formação específica e geral preconizados pela Lei 5692/71 e suas sucessivas "reformas", até a última reforma da LDB (BERTICELLI, 1998, p. 14-15).

A partir do exposto por Berticelli (Ibid.), entende-se que temos senão o princípio de que existe um ser universal 1, uma formação integral do homem a ser garantida, num lugar especial, propriamente único, que é a escola. Esta é a base para a compreensão de como a educação responde ao nascimento das crianças.

Para tanto, falar de infância,

não diz respeito apenas e/ou simplesmente às formas como as crianças são entendidas, mas às formas como elas são entendidas na sua relação com adultos e na relação destes todos (crianças e adultos) com as maneiras pelas quais o mundo em que vivem é por eles ordenado (COUTINHO, 2002).

Isso significa dizer que há uma compreensão de infância que não se dá por ela mesma, mas num rol de relações, principalmente, com os adultos, pois são os "responsáveis" diretos pelos cuidados e educação da criança. Significa, ainda, descartar o conceito de um modelo de criança presente num mundo idealista, platônico em que se concebe um modelo imutável do ser, centrado em si, sujeito ideal, e a partir deste supostos os demais devem partir para sua afirmação como sujeito. Para entender a criança, é preciso compreender a noção de sujeito moderno que se constitui num exercício extremamente complexo, “(...) a idéia de que as identidades eram plenamente unificadas e coerentes e que agora se tornaram deslocadas é uma forma altamente simplista de contar a estória do sujeito moderno" (HALL, 1992, p. 26). A individualidade humana que emergiu na modernidade não desconsidera, em tempos anteriores, que as pessoas não eram indivíduos, mas a individualidade era vivida e conceituada diferentemente.

Nesse sentido, na medida em que na modernidade surge o homem moderno, em momento particular podemos falar sobre seu "nascimento" e, considerando nesse momento, a existência de uma história. 
Analisamos aqui, o ser humano moderno como um fenômeno, assim permite-se reforçar acerca de uma história que não é linear, e sim descontínua, pois os momentos históricos não são sempre os mesmos. Desse modo, as diferentes concepções de identidade, cada uma em seu tempo histórico, indicam o "nascimento" e a "morte" do sujeito acima descrito.

A "morte" do sujeito iluminista - individualizado e natural - por exemplo, representou o "nascimento" do sujeito sociológico - no qual a identidade era entendida como o produto da interação social e o 'eu interior', portanto, histórico. Hall (Ibid., p. 11) pontua que,

(...) o sujeito do Iluminismo está baseado numa concepção de pessoa humana como um indivíduo totalmente centrado, unificado, dotado das capacidades de razão, de consciência e de ação, cujo centro consiste num núcleo interior, que emergia pela primeira vez quando o sujeito nascia e com ele se desenvolvia ainda que, permanecendo essencialmente o mesmo - contínuo, idêntico a ele ao longo da existência do indivíduo. O centro essencial do eu era a identidade de uma pessoa.

E diz que,

(...) o sujeito sociológico refletia a crescente complexidade do mundo moderno e a consciência de que este núcleo interior do sujeito não era autônomo e auto-suficiente, mas era formado na relação com outras pessoas importantes para ele, que mediavam para o sujeito os valores, sentidos e símbolos - a cultura - dos mundos que ele/ela habitava.

Notamos, então, um sujeito que é negado e, ao mesmo tempo, substituído por outro. Não é uma mera desconstrução do ideal proposto pela modernidade, é a proposição de um novo entendimento acerca do sujeito. O ser humano só existirá a partir de uma subjetividade construída socialmente, que são as identidades. O interessante é que, a partir desse momento, nessa perspectiva, podemos falar não apenas de "homem", mas de criança, mulher, louco, professor(a), etc., porque o 
que passa estar em discussão não é um único ser, ideal e centrado em si próprio, mas as identidades que socialmente se constroem, ou seja, a identidade da mulher, a identidade da criança, a identidade do louco, a identidade de professor(a), e cada identidade será diferente em determinado momento histórico, conforme onde se encontram os sujeitos.

\section{As características e organização do espaço educativo}

Com as análises empreendidas até aqui, é possível iniciar este debate que propomos em torno da relação entre espaço e disciplina, estando em consonância com o sujeito dessa investigação: a criança. Nessa direção, a imagem a seguir é bem significativa.

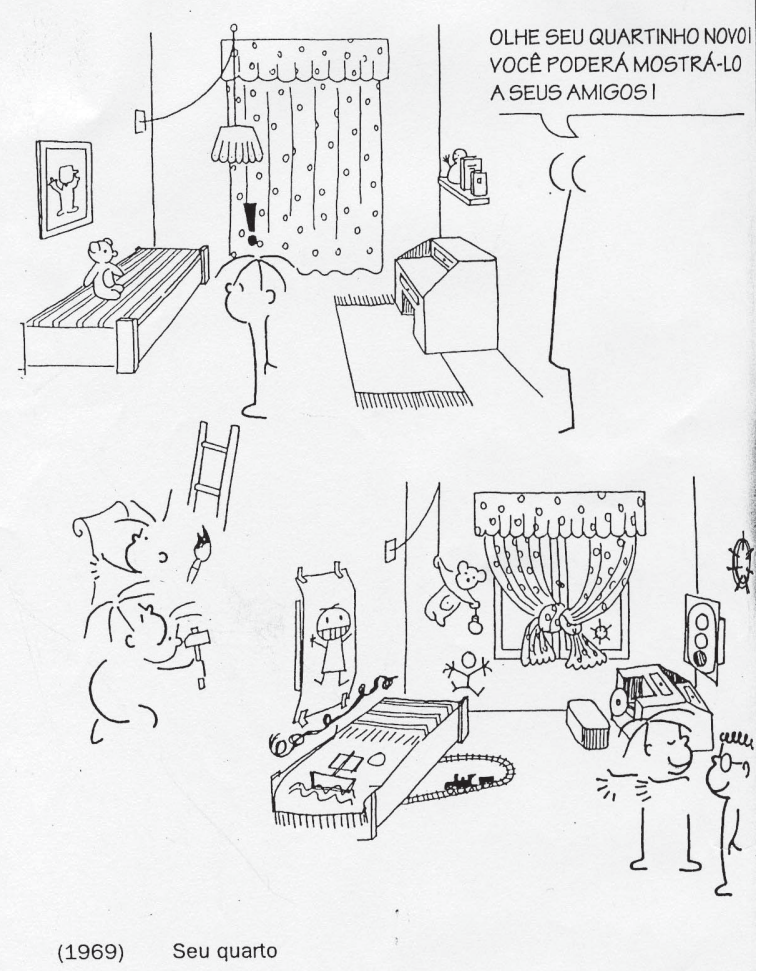

TONUCCI, F. Com olhos de criança. Porto Alegre: Artes Médicas.1997. 
A cena que vemos, a partir da imagem, refere-se a uma criança com sua mãe, parados, a mãe na porta e a criança mais a frente. A visão que tem é a do quarto da criança. Tudo no seu devido lugar, "organizado"; cortinas, tapete, escrivaninha, abajur, brinquedos. A sensação da mãe parece ser de empolgação, também parece orgulhosa; seu comentário expressa isso: "Olhe seu quartinho novo! Você poderá mostrá-lo a seus amigos!” Já a expressão da criança não parece estar nem um pouco empolgada; olhos e ombros caídos denotam sua tristeza em ver toda aquela "arrumação".

A cena que segue, mostra a interferência da criança no quarto, o "quartinho novo" do jeito que ela queria, e que em nada se parece com o da mãe. Só depois disso é que faz questão de receber seu amigo e o convidar para entrar.

Foi mais ou menos desta forma que encontramos o espaço educativo que mencionamos no início do texto.

De certa forma, assim como a mãe da charge, a professora apresentava às crianças seus "quartinhos", ou seja, os espaços na sala de aula. Esta apresentação se dava de maneira parecida com expressões do tipo: "Agora vamos para o cantinho da leitura". A partir disso, foi possível iniciar o debate.

Afinal de contas, o que é espaço? Para que ele serve? Analisando o sentido semântico apresentado por Forneiro apud Zabalza (1998, p.230), vemos que espaço significa “(...) extensão indefinida, meio sem limites que contém todas as extensões finitas. Parte dessa extensão que ocupa cada corpo". Esse conceito de espaço pressupõe algo físico que pode ser preenchido por objetos. Uma "caixa" que pode ser ocupada é uma forma abstrata de ver. Essa visão é extremamente comum entre os adultos, no entanto a criança percebe o espaço de forma diferente, para ela não existe a abstração de algum lugar, apenas o espaço, e tudo o que pode ser colocado nele, ou seja, espaço são equipamentos, móveis, cores, etc. Para os adultos, essa percepção é a do espaço já equipado.

Segundo Harvey (1996, p.188),

(...) o espaço também é tratado como um fato da natureza, "naturalizado" através da atribuição de sentidos cotidianos 
comuns. Sob certos aspectos mais complexo do que o tempo tem direção, área, forma, padrão e volume como principais atributos, bem como distância -, o espaço é tratado tipicamente como um atributo objetivo das coisas que pode ser medido e, portanto, apreendido.

Nesse sentido, o espaço pode ser compreendido em conformidade com a noção de ambiente apontada por Forneiro (1998, p.232), o qual postula que o ambiente é o conjunto do espaço físico e mais a relação que se estabelece nele. Estas relações descrevem-se como afetos, relações interpessoais entre as crianças, entre crianças e adultos, entre crianças e a sociedade em seu conjunto. Portanto, o espaço não é neutro. Ele permeia as relações estabelecidas, influenciando-as, na medida em que chega até o sujeito e propõe suas mensagens implicitamente.

Verificamos, pois, que espaço é tudo e indissociado da noção de ambiente. Indo um pouco além desta visão formal e utilitária do espaço, podemos percebê-lo também como um “(...) espaço de vida, no qual a vida acontece e se desenvolve: é um conjunto completo”. Essa visão pode ser considerada vitalista, porque se adapta à forma que a criança vê o espaço, pois ela o sente e o vê, portanto "(...) é grande, pequeno, claro, escuro, é poder correr ou ficar quieto, é silêncio, é barulho" (BATTINI apud FORNEIRO, 1998, p.231). A criança não o concebe abstratamente, pois ainda não tem desenvolvida esta capacidade. $\mathrm{O}$ que a criança pode ver restringe-se ao concreto, ao palpável.

Tonucci (1997) expressa algo bem simples na charge: a criança vê o espaço da sua casa como algo concreto e, a partir do seu imaginário infantil, o lugar para ela só é atrativo se puder interagir e vivenciar o brincar. Com isso, percebemos que a infância é uma etapa diferenciada do mundo adulto, portanto o seu modo de ver a vida é baseado no poder de manipular os objetos e criar formas lúdicas com eles. Tonucci (Ibid., p.68) faz uma leitura crítica, a partir de imagens sobre a influência que a escola e família exercem sobre a criança, procurando organizar o mundo dela com bases na noção de mundo do adulto. Cabe aos professores o olhar atento para as especificidades do sujeito infantil e organizá-lo de maneira que contemple o jogo, o brincar, e o despertar 
do imaginário infantil, buscando evidenciar, em sua prática pedagógica, as múltiplas linguagens. $\mathrm{O}$ espaço educativo deve ser prazeroso e voltado às necessidades de cada faixa etária na primeira infância.

\section{Como está organizado o espaço educativo da pré-escola?}

Com todas estas observações em mente, "mergulhamos" na pesquisa de campo. Investigar a realidade da escola no que se refere à organização do espaço educativo implicou abordar a distribuição dos objetos/materiais, a relação das crianças no espaço, a utilidade e função da organização do espaço educativo e disposição dos materiais didáticos e pedagógicos quanto à necessidade e manuseio pelas crianças. No que se refere à distribuição dos objetos/materiais, constatou-se a divisão da sala em espaços, como: o do brincar, o cantinho da história, o cantinho da higiene e o espaço de atividades pedagógicas1. Cada um com seus objetos e materiais característicos.

Verificamos ainda que a relação das crianças com o espaço ocorreu de forma que pudemos denominar de entusiasmada, pois havia direcionamento de atividades pela professora. No momento de brincar, utilizam-se do espaço do brincar, da higiene, e das mesas quando a jogos de montar nelas.

Ficou evidente a utilidade e função da organização do espaço educativo, que auxiliou no controle, por parte da professora, das atividades e das crianças. A visibilidade dos espaços, através de uma disposição harmônica das coisas, ou seja, uma disposição que permite que cada canto possua as suas características e funções próprias contribuem para o planejamento das atividades. Há dinamismo na passagem de uma atividade para outra. Carvalho e Rubiano apud Oliveira (1996) auxiliam na compreensão quando afirmam que “(...) fatores físicos podem influenciar o comportamento facilitando certas atividades e obstruindo outras". No caso da educação infantil, um exemplo dado para obstrução de uma atividade é pela ausência de passagem ou caminhos claros para uma área de atividade, o que, em geral, resulta na dificuldade da utilização dos espaços. No espaço pesquisado, verificamos que não há maiores problemas por essa questão. No espaço pedagógico, estava em destaque o quadro de giz, 
as carteiras e cadeiras, dando a ele uma função marcadamente escolar. O ensino das letras e números é realizado preponderantemente, e a preocupação com a alfabetização das crianças é manifesta no discurso da professora e na prática, no entanto revela que é importante o brincar na educação infantil. Os painéis do alfabeto e algarismos, próximos ao espaço da atividade pedagógica, revelam uma utilidade escolarizante para este espaço.

De modo geral, verificamos que as demarcações espaciais são visíveis na organização do espaço. Uma delimitação quase que precisa, dizendo "aqui redijo tais atividades e ali estas outras", mas há uma demarcação que é invisível e que está intrínseca nas crianças. Ao brincar, a criança procura permanecer no cantinho do brincar; ao fazer atividades dirigidas (desenhar, pintar, escrever), utilizam-se do quadro de giz ou das mesas.

\section{A organização do espaço educativo e as práticas de disciplinamento: algumas análises}

Para o estabelecimento da análise do espaço educativo da Escola Básica Municipal Peter Pan1 e do disciplinamento infantil, deslindam-se as categorias foucaultianas sobre as práticas disciplinares, citamos: a arte de distribuição, a organização das gêneses e a composição de forças. Estes conceitos foucaultianos nos ajudaram a compreender como o espaço educativo colabora no disciplinamento da criança. $\mathrm{O}$ espaço físico da sala de aula da turma de pré-escola estava organizado com as seguintes denominações:

-> à Espaço do brincar

Cantinho da história;

Cantinho da higiene;

-> à Espaço da atividade

Cantinho do quadro de giz;

Cantinho dos materiais didáticos.

-> Ao produzir o projeto sobre a organização do espaço físico da educação infantil e o disciplinamento da criança de quatro a seis anos, nos questionávamos: Quais seriam as estratégias de disciplinamento das crianças no espaço infantil da educação infantil? Essa indagação nos 
levou a observar que a forma de organização do espaço estava relacionada de maneira marcante ao espaço no disciplinamento das crianças. Portanto, em se tratando de um espaço educativo, constatamos que ele é um lugar retangular, planejado, organizado, ordenado, estabelecendo de maneira disciplinada os móveis e objetos. Cada objeto em seu lugar determinado. Há o espaço do brincar e de contar histórias, também há espaço para as atividades e para o lanche. Estabelecendo de maneira disciplinada os móveis e objetos. Cabe salientar aqui que, juntamente com a forma disciplinada dos equipamentos da sala de aula, há a disciplina do tempo. Tem-se a organização do tempo em determinada atividade e espaço para cada momento da aula.

-> É por essa razão que a essa pesquisa cabe focalizar o termo disciplinamento como categoria central de análise e também como parte integrante da educação das crianças em idade de educação infantil. Sobretudo, no espaço, o disciplinamento é imprescindível. Ele permitirá atingir o objetivo de compreender quais são as estratégias de disciplinamento, pois é através dele que poderemos observar as ações possíveis de auto-regulação da criança no espaço educativo e seus mecanismos para essa ação. Logicamente, não se pode descartar o contexto como influente, porém, a estrutura social e político-educacional está de tal forma posta e desenvolvida, ao longo da história, que "autoriza" a educadora, através dos próprios elementos constitutivos da sala (carteiras, materiais didáticos, disciplinas, regras de convivência e obediência), às práticas de disciplinamento. Isso pressupõe pensar que desde os primórdios da modernidade o homem preocupa-se com a questão da disciplina.

\section{A produção da disciplina}

A produção do que chamamos de disciplinamento em nossas análises até aqui, refere-se ao que Foucault denomina de poder disciplinar; poder este que é marcado pela construção das ações do corpo humano como forma de auto-regulação ou disciplinamento.

Em sua obra Vigiar e Punir, Foucault (1987) analisa a história da violência nas prisões e trabalha a evolução de métodos coercitivos e punitivos para a repressão dos delinquentes e criminosos. No século 
XVII, a forma de coagir e punir os marginais eram execuções políticas como torturas e suplícios repugnantes. Devido à ênfase na humanização, na necessidade de criação de códigos penais menos rigorosos e mais eficientes, vem desaparecendo o corpo como alvo principal de repressão penal, pois reprimir, torturar causaria mais violência. Pensamos, então, na punição camuflada, uma punição de "consciência abstrata"1, pois os indivíduos devem se auto-controlar, auto-punir, para que o sistema penal não o faça.

$\mathrm{O}$ autor descreve que, na época clássica, há uma descoberta da produtividade do corpo, visto como objeto e alvo de poder. O corpo como objeto compreende a sua análise de utilização para a experiência, disciplinando-o, analisando-o, para posteriormente torná-lo útil. No início do século XVII, descrevia-se a figura ideal de soldado, capaz de lutar, ser valente, corajoso, possuir um porte corporal para um homem de honra. O soldado deveria ser conhecido de longe (Ibid., p. 117). Na segunda metade do século XVIII, o soldado tornou-se algo que se fabrica e para isto precisaria ser manipulado, docilizado, treinado para ser obediente e hábil. No século XVIII, apresentam-se novas técnicas de investimento sobre o corpo, buscando torná-lo analisável. O corpo passa a ser um instrumento analisado, estudado, manipulável, treinado, transformado, modificado e isto se dá pela coerção sem folga dos movimentos dos sujeitos. Só é dócil o corpo que pode ser utilizado, analisado, submetido e maquinado. Corpo visto como máquina que se constrói de acordo com a sua utilidade e docilidade.

Estudar o corpo compreende relações de poder "(...) muito apertado, que lhe impõem limitações, proibições ou obrigações" (Ibid, p.118). Em qualquer sociedade há um perfil de homem e de mulher que se quer produzir de acordo com a situação política, social, e econômica em que se inserem. No entanto, há necessidade de se treinar, adequar, utilizar, e desenvolver as habilidades almejadas. As relações de poder que cerceiam tais práticas procuram limitar, definir e obrigar o corpo a se modelar no perfil exigido. O bom soldado é aquele que é útil e dócil para o governo, aquele que o corpo já se disciplinou a identificar os sinais de comando (postura ereta, marchar correto, praticar todos os exercícios, entre outros). Na escola, o "bom” aluno é aquele que, quando bate o sinal, já foi ao banheiro e lavou as mãos, 
levanta o dedo toda vez que precisa falar, é de poucas palavras, aprende com facilidade, é comportado, faz o tema ou dever de casa todos os dias, entre outras.

Para que ocorra a dominação do corpo, é enfatizado o controle minucioso das suas ações, é preciso controlar, reprimir sobrepondo-o ao mesmo nível da mecânica, explorando todos os movimentos, gestos, atitudes e rapidez. Com o controle das ações do corpo, através da eficácia nos movimentos e de sua organização interna, o corpo se torna útil-dócil e econômico. Sua produtividade econômica é garantida com exercícios, priorizando uma intensa atividade física em consonância com a apropriação máxima do tempo, espaço e movimento. Para o autor (Ibid., p.118), ao se exercitar a disciplina em termos econômicos e de utilidade, a disciplina aumenta a força do corpo e diminui essas mesmas forças em termos de obediência. Esses métodos que permitem o controle minucioso das operações do corpo, que realizam a sujeição constante de suas forças e lhes impõem uma relação de docilidadeutilidade, são o que podemos chamar as "disciplinas", ou seja, elas se tornaram no decorrer dos séculos XVII e XVIII, fórmulas gerais de dominação.

As disciplinas já existem há muito tempo, e, em toda a esfera social, tornam-se uma maneira de dominação, tendo como objetivo principal o aumento do domínio de cada um sobre si, sobre seu próprio corpo. O corpo disciplinado é analisado como uma "maquinaria de poder" (Ibid., p. 119) que o examinam intensamente, o desarticulam, e o recompõe. A disciplina tem sua eficácia pelo fato de procurar controlar as pequenas ações dos indivíduos, é a "anatomia política do detalhe" controlando minuciosamente o corpo. Desde a era clássica, através da teologia, procurava-se corrigir as pequenas coisas para alcançar a perfeição divina. Os sujeitos sempre foram alvo de estudos, ou melhor, seus comportamentos, tendo como principal interesse um corpo dócil e produtivo.

Ao fabricar corpos obedientes e exercitados, ou melhor, corpos "dóceis", a disciplina aumenta, por um lado, as aptidões e as capacidades, e, por outro, diminui a energia, a potência que poderia resultar delas e criar uma sujeição restrita. Em consequência, no corpo, estabelece-se uma ligação repressiva entre aptidão aumentada e uma 
dominação acentuada. As disciplinas ou poder disciplinar historicamente se estabelecem como prática de poderes vinculados às formas de conhecimento, e se espalham por todo corpo social nas mais diversas instituições. Salientamos, portanto, que, para Foucault (apud ASSMANN; NUNES, 2000, p.136), o poder moderno, embora tenha seu caráter repressivo e violento é extremamente positivo e produtivo.

\section{Algumas análises do disciplinamento no espaço educativo}

A partir das ideias de Foucault, é possível perceber que a disciplina é um tipo de organização, de técnicas de distribuição dos corpos infantis nos espaços escolares, e que visa a espaços individualizados, classificatórios e combinatórios, a fim de que as práticas disciplinares se incorporem aos sujeitos. Para Assmann e Nunes (2000, p. 38), “(...) trata-se de fechar, enclausurar, esquadrinhar, hierarquizar para arrumar, sendo esta técnica capaz de realizar funções diferentes dependendo do objetivo específico que dela se exija". Há a necessidade de fechar para poder organizar, pois é necessário anular as repartições indecisas, a circulação difusa, a anti-aglomeração entre as crianças no espaço educativo.

O espaço observado tem essa função à medida que distribui as crianças em "cantinhos", sendo que cada um tem suas funções. A disciplina presente no espaço educativo pesquisado é percebida através da organização dos espaços em que se corrobora a constituição do espaço do brincar e da atividade, juntamente, com a organização do tempo, colaborando na não difusão das crianças pelo espaço educativo. Isso ocorre, uma vez que, ao adentrarem ao espaço do brincar, as crianças permanecem ali, evitando saírem para brincar em outros lugares e também de produzirem outros espaços de brincadeiras. Quando estão no espaço da atividade, fazendo suas produções, também permanecem sentadas ouvindo o que a professora lhes diz. Cabe aqui o seguinte questionamento: em que outros lugares manifesta-se o brincar para além do cantinho específico? No parque? Na quadra ou no campo? No espaço da atividade pedagógica? Na comunidade? O que é brincar para a infância? E para o (a) professor (a)?

Cada espaço tem sua função. Para Foucault (1987, p. 123), na 
categoria arte das distribuições, denomina uma subdivisão intitulada de localização funcional, que tem como pressuposto compreender os espaços disciplinares como espaços úteis.

(...) nas instituições disciplinares, codificar um espaço que a arquitetura deixava geralmente livre e pronto para vários usos. Lugares determinados que definem para satisfazer não só a necessidade de vigiar, de romper as comunicações perigosas, mas também, de criar um espaço útil (idem).

A organização do espaço colabora na criação de espaço útil, pois, em determinado momento, as crianças dirigem-se aos cantinhos e deles é possível obter-se o máximo de proveito, para que, assim, a professora possa realizar seu trabalho com rapidez e eficiência, além de controlar as crianças. Para exemplificar, no espaço de atividades, as crianças recortam, pintam, desenham, aprendem as letras e números; no espaço do brincar, as crianças montam jogos, representam e imitam papéis sociais; entendemos que cada espaço tem sua função e ele deve colaborar na utilidade econômica do corpo e torná-lo docilizado em relação ao ambiente. A organização do espaço estabelece uma lógica moderna de lugar e ele tem em si discursividades que o constitui. Para tanto, salientamos que o espaço educativo da educação infantil, com seus espaços funcionais1, é subjetivo, pois sua organização é feita pela professora e visa à formação de um ideal de criança. Assim, verificamos que a distribuição das crianças nos espaços funcionais, que não deixam de ser espaços quadriculados, não precisamente geométricos, mas sim codificados, ajudam a professora a vigiar e a visualizar todas as crianças ao mesmo tempo.

Coutinho (2002) destaca que quanto maior a criação de espaços e a organização do tempo, mais a eficácia do poder disciplinar. Pois, a rigidez do tempo (hora de brincar, hora disto, hora daquilo) e a criação do espaço do brincar, espaço da literatura, espaço dos jogos de montar, espaço de atividades colaboram no controle e na disciplina dos corpos infantis. A disciplina se efetiva no controle do tempo e na organização do espaço.

Outro aspecto abstraído da nossa observação, é sobre as demarcações espaciais do espaço educativo da turma de educação 
infantil da escola, as quais possuem um cerceamento, ou melhor, um quadriculamento simbólico, na medida em que elas, ao serem conduzidas ao espaço do brincar, ali ficam como se fossem reguladas a não passarem pelas demarcações 2 desse espaço. Algo que nos chamou a atenção foi o fato da professora anunciar para as crianças irem brincar nos espaços (da higiene e literatura), e que ela colocaria uma caixa com jogo de montar em cima da mesa para que eles montassem. Observamos que as crianças que brincavam no espaço da literatura saiam desse espaço para ir brincar no espaço da higiene, mas dificilmente elas criavam outros espaços fora destes lugares. Ao brincarem com jogos de montar, as crianças ficavam em cima da mesa ou no chão, uma próxima da outra, explorando pouco o espaço educativo como um todo. No espaço da atividade, as crianças desenvolviam seus trabalhos na mesa em grupos de quatro crianças e ao fazer as atividades propostas pela docente permaneciam sentadas e dificilmente saiam de suas cadeiras, enquanto não concluíssem.

Para clarificar esta problemática, Coutinho (2002) explana que “(...) o cercear e o cercar não exigem, necessariamente, cercas físicas, no sentido material. (...) o espaço também pode perfeitamente ser quadriculado, dividido, cerceado e cercado simbolicamente". Concebemos no espaço educativo da Escola Básica Municipal Peter Pan, um quadriculamento simbólico, em que as crianças ficam nos espaços montados como se houvessem cercas materiais. Logo, ressaltamos que as disciplinas são estes instrumentos de poder, técnicas, mecanismos e dispositivos atrelados à organização do espaço educativo, fazendo com que as crianças sejam disciplinadas a ficar em determinados lugares simbolicamente.

Quando lemos Kant (1996, p. 16), vemos que “(...) a falta de disciplina é um mal pior que a falta de cultura, pois esta pode ser remediada mais tarde, ao passo que não se pode abolir o estado selvagem e corrigir um defeito da disciplina". Com isso, podemos perceber o embasamento das ações educativas observadas. Refletimos sobre esse pensamento de Kant, com o intuito de promover um debate sobre a disciplina na escola, mas não há a pretensão de salientar se autor está correto ou não. Kant (Ibid.) foi o primeiro a caracterizar a escola moderna como responsável pelo disciplinamento dos corpos 
infantis nos espaços da instituição, concebendo que a disciplina impede o homem de desviar do seu caminho, tendo como dever, estreitá-lo, contê-lo, e através da educação instrumentalizá-lo para que retorne ao seu estado humano. Ou seja, toda e qualquer manifestação de indisciplinamento às normas, torna o homem selvagem, animal. A disciplina submete o homem às leis da humanidade e o faz sentir a sua força, mas todo este processo de disciplinamento deve acontecer bem cedo, sendo assim, as crianças devem ser mandadas ainda pequenas à escola para que a disciplina tenha seu efeito sobre o seu corpo.

Foucault (1987, p. 140), ao abordar sobre a educação escolar, pontua que,

A escola torna-se um aparelho de aprender onde cada aluno, cada nível e cada momento, se estão combinados como deve ser, são permanentemente utilizados no processo geral de ensino. (...) $\mathrm{O}$ treinamento de escolares dever ser feito da mesma maneira; poucas palavras, nenhuma explicação, no máximo um silêncio total que só seria interrompido por sinais - sinos, palavras, gestos, simples olhar do mestre, ou ainda aquele pequeno aparelho de madeira que os Irmãos das Escolas Cristãs usavam; era chamado por excelência o "sinal" e devia significar em sua brevidade maquinal ao mesmo tempo a técnica do comando e a moral da obediência. (...) O aluno deverá aprender o código dos sinais e atender automaticamente a cada um deles.

Para Assmann e Nunes (2000, p.138), a arte das distribuições, uma categoria foucaultiana sobre as práticas disciplinares, pressupõe que “(...) a disciplina é um tipo de organização do espaço”. Ela é uma distribuição dos sujeitos nos espaços escolares. O espaço educativo da educação infantil trata-se de fechar, esquadrinhar e, por vezes, cercar estes lugares geometricamente, para que não ocorra difusão das crianças. Para auxiliar nesta compreensão, Duclós (2003) enfatiza que a geometria cartesiana pauta-se na importância da ordem e da medida. Para Descartes (1996), na geometria não há dúvidas, pois ela é universal e simples. Assim, constitui-se a modernidade e as formas da organização do espaço educativo como verdades únicas, obtendo- 
se, através das disposições dos materiais e objetos pedagógicos, uma lógica capitalista, moderna, geométrica, pautando-se na importância da lógica matemática. Podemos dizer que o espaço educativo é organizado de forma planejada e ordenado dentro de uma lógica moderna de espaço e tempo.

Contudo, a educação atual está forjada aos discursos pedagógicos do século XVII, pois nas escolas e Centros de Educação Infantil, muitas vezes, força-se a criança a obedecer atenciosamente o que lhe foi ordenado, devendo ficar sentada na hora de fazer atividade ou na hora de brincar. Logo, a criança deve voltar-se ao que a professora pontua, não podendo assim fazer outras coisas. A criança, desde cedo, é adaptada ao modelo escolar na educação infantil, uma vez que, na hora de fazer a atividade, deve ficar sentada e atenta ao que a professora está explicando. As que fogem às regras são consideradas sem limites, sendo preciso garantir mecanismos que façam as crianças a disciplinarizarem-se em relação ao espaço e ao tempo da sala. Podemos considerar uma assertiva proposta por Kant (1996, p. 19), na qual ele destaca que a criança se torna criança, homem, mulher pela educação e ela é aquilo que a educação faz dela.

\section{Algumas considerações finais}

É central dizer aqui que a escola é um espaço que não é neutro. Do mesmo modo ocorre com as instituições de educação infantil. A não neutralidade é comprovada quando se verifica que, através da organização e de sua ocupação, planeja-se, e as propostas de trabalho são desenvolvidas. A criança que integra algum espaço educativo passa a ser "educada" e relacionar-se com os objetos e materiais ali presentes, acarretando, consequentemente, na modificação de seu comportamento, ou seja, tornando-se disciplinado. Quando se aborda a questão do disciplinamento, a primeira impressão é a do sentido pejorativo a que esta palavra nos remete, porém, esta categoria contribuiu significativamente na elaboração das análises, pois não possui conotação negativa. Foucault (1987) ajuda a compreender esta questão, quando postula que a disciplina é um tipo de organização. Acrescenta que a disciplina é um conjunto de técnicas de distribuição dos corpos 
infantis nos espaços escolares e que tem como objetivos espaços individualizados, classificatórios e combinatórios, a fim de que as práticas disciplinares se incorporem aos sujeitos.

Compreende-se, na pesquisa realizada, a intrínseca relação existente entre organização do espaço e disciplinamento da criança através da ação da professora. Ao pensar espaços divididos por funções - os cantinhos - para a educação infantil, a professora torna-os úteis e produtivos ao seu planejamento, no sentido de que auxilie na condução das atividades. São espaços individualizados, porque representam atividades específicas como ouvir história, por exemplo, e, por isso, são também espaços funcionais (úteis a funções específicas determinadas pela professora). Além disso, verifica-se a ocorrência de tempo determinado para cada atividade.

A partir dessa explanação, podemos ponderar a disciplina da criança em relação ao espaço. Isso significa que a criança incorporará os espaços e suas delimitações invisíveis, e circulará por eles nos momentos determinados pela professora. O disciplinamento se manifestará na criança quando ela não abandona o espaço da atividade que a professora propôs para aquele momento; não havendo exploração do espaço como um todo, mas dentro de limites que são demarcações invisíveis. Além de ter incorporado para si aquela demarcação, a criança é capaz de "vigiar" o seu colega. Neste último fato reside, ainda, outra categoria foucaultiana de análise importante: o controle. Voltando ao papel da professora nesse processo, o controle é resultado da organização harmônica e precisa dos espaços, individualizando-os e tornando-os funcionais. O campo de ação e controle sobre as crianças será maior quanto menor for o espaço que está sendo utilizado. Isso quer dizer que a professora pode intervir mais facilmente em diversos momentos: quando uma criança tenta fugir do espaço para ir a outro, quando há disputa de brinquedo, quando há desentendimentos corriqueiros entre as crianças, ou até mesmo para concretizar o processo pedagógico a que se propõe.

Ressaltamos que nosso interesse não está em verificar erros e negatividades do espaço educativo, da direção da escola, das professoras, ou da família sobre a educação ou socialização das crianças, e muito menos apontar falhas no discurso educacional da 
escola. Nosso estudo não se trata de nenhuma acusação à instituição e ao profissional envolvido, pois temos como mérito de pesquisa as relações e novos olhares para suscitar o debate acerca da organização do espaço educativo. Reiteramos que a incorporação da disciplina pela criança se dá imperceptivelmente. Tornam-se exercícios repetitivos de condução do tempo em cada espaço, e isso pode ser constatado quando encontramos falas semelhantes a "agora é hora de história", ou "agora é hora de brincar no parque". Não aprofundamos em nosso trabalho a questão do tempo, mas, podemos torná-lo intrínseco à organização do espaço e à condução das atividades, pois espaço e tempo estão indissociáveis nas formas como são estruturadas as propostas pedagógicas.

A educação infantil é um tempo diferente do tempo do ensino fundamental. Portanto, concebemos a necessidade na projeção de espaços físicos que atendam o desafio e a particularidade do momento de "ser criança" e da necessidade que elas participem da organização do espaço e tempo, estabelecendo com os profissionais que atuam com ela momentos de interação e decisórios na produção destes. A criança precisa encontrar no espaço educativo algo que não seja uma pré-escolarização "etapa antecipatória do ensino fundamental", mas sim um ambiente que prime pela suas especificidades e nele encontre a apropriação das diferentes linguagens e não somente pela primazia da linguagem oral e escrita e matemática, mas destas entrecruzadas com as outras formas de expressão, representação e de conhecimento do mundo pelas crianças. Ressaltamos que, ao adentrar o espaço educativo da sala de aula da pré-escola pesquisada, identificamos uma predominância espacial muito similar ao do ensino fundamental, ou seja, a ênfase manifesta, em maior proporção, o ambiente ao espaço de atividades pedagógicas para "trabalhinhos", em que se encontra a aquisição da leitura e da escrita e de alguns símbolos matemáticos.

A forma como a criança percebe o espaço é diferente da lógica do adulto. O adulto o organiza, muitas vezes, não considerando a relevância da participação da criança na construção dele. Outra perspectiva para a organização do espaço, na educação infantil, pode ser produzida a partir da mudança de foco da proposta pedagógica, tendo a criança na centralidade do processo educativo, superando, assim, a lógica 
adultocêntrica do pensar e organizar o espaço e o tempo sem considerar, muitas vezes, o olhar sensível às necessidades das crianças e seus modos de agir. Félix Guattari (1987) traz este posicionamento, quando discorre que "O que conta na creche, insistimos nisso, não é a técnica, é o efeito da política semiótica dos adultos sobre as crianças”. Cabe aos (as) professores (as) o olhar atento às especificidades do sujeito infantil e, juntamente com a criança, organizarem o espaço de maneira que contemple o jogo, o brincar, e o despertar do imaginário infantil. $\mathrm{O}$ espaço educativo deve ser prazeroso e voltado às necessidades de cada faixa etária na primeira infância.

A infância é produzida através de subjetivações e não se evidencia o estabelecimento da existência de uma única ideia e correta sobre a criança, mas sim na sua relação com os familiares, professores/as e amigos/as. A infância é algo de nossos saberes, de nossas tecnologias (LARROSA, 1998, p. 68). Portanto, o espaço escolar é estabelecido dentro da lógica moderna de espaço fixo, sendo constituído e organizado através de discursos pedagógicos - cujo foco é o adulto e suas formas de ver e se relacionar com a criança - permeados por subjetividades. Evidenciamos, à luz das leituras e das análises realizadas, que, nos Centros de Educação Infantil, as salas de aula têm fortes marcas "escolarizantes" (carteiras e cadeiras, quadro de giz e atividades pedagógicas). Os espaços podem, muitas vezes, serem organizados em espaços funcionais, ou seja, espaços construídos pela professora destinados a funções específicas, como o cantinho do brincar, das atividades pedagógicas, e da leitura, propiciando, assim, o disciplinamento da criança. Essa diferença de perspectivas para a organização do espaço educativo reflete diferenças na concepção do trabalho a ser desenvolvido, e implica em elementos qualitativamente distintos, como: se a centralidade está na atividade da criança, ou na lógica do adulto; se está no desenvolvimento e expressão das diferentes linguagens possíveis na infância, ou nos exercícios repetitivos de ênfase cognitivista.

\section{Notas}

${ }^{1} \mathrm{O}$ presente trabalho é resultado de uma pesquisa iniciada no ano de 2003 e concluída em 2004, em uma escola de Ensino Fundamental que atende turmas dos anos iniciais e 
Educação Infantil, mantida pelo poder público municipal, na cidade de Chapecó - SC. Em 2003, iniciávamos a nossa inserção no mundo da investigação dirigindo nosso olhar sobre a infância e a educação infantil, no que tange a organização do espaço físico e o disciplinamento da criança.

2 Pedagoga habilitada em educação infantil UNOCHAPECÓ. E-mail: ale@unochapeco.edu.br

${ }^{3}$ Mestranda em Educação pela UNIVERSIDADE FEDERAL DE SANTA MARIA. Email: dorkass@desbrava.com.br

${ }^{4}$ Doutor em educação pela Universidade Federal do Rio Grande do Sul. Professor da Universidade Comunitária da Região de Chapecó: Unochapecó. E-mail: ibertice@unochapeco.edu.br

${ }^{5}$ Conforme estudos realizados por Eloísa Rocha (1999a), na sua tese de doutoramento, em que ela analisa na década de 1990, novas temáticas e pesquisas envolvendo a área de Educação Infantil, apresentadas em congressos científicos.

${ }_{6}$ A pesquisa contou com a orientação do prof. Dr. Ireno Antonio Berticelli (Professor da Universidade Comunitária Regional de Chapecó - UNOCHAPECÓ);

${ }^{7}$ Grifo nosso.

${ }^{8} \mathrm{O}$ espaço das atividades pedagógicas; espaço do brincar: cantinhos da higiene e cantinho da história; são terminologias utilizadas pela professora da sala e consideramos utilizálos para sermos fidedignas aos dados coletados e as análises.

9 Nome fictício da instituição pesquisada em Chapecó/SC.

${ }^{10}$ IFOUCAULT, (1987, p. 13)

${ }^{11}$ Expressão cunhada a partir das expressões: "cantinhos funcionais" Coutinho (2002) e "localização funcional" Foucault (1987).

12 Demarcação que, na verdade, é simbólica.

\section{Referências}

ASSMANN, Selvino José; NUNES, Nei Antonio. A escola e as práticas de poder disciplinar. In: Perspectiva, Florianópolis, v. 18, n.33, p. 135 - 153, jan/jul.2000.

BERTICELLI, Ireno Antônio. Da escola utópica à escola heterotópica: Educação e pós-modernidade. In: Educação \& Realidade, Porto Alegre, n.01, v. 23, p. 13-24. jan./jun.1998.

BRASIL. [Leis, etc.].. LDB: Lei de Diretrizes e Bases da Educação : Lei n 9.394/ 96. 6. ed. Rio de Janeiro: DP \& A, 2003.

CARVALHO, Mara I. Campos de; RUBIANO, Márcia R. Bonagamba. Organização do espaço em instituições pré-escolares. In: OLIVEIRA, Zilma M. Ramos de (org.). Educação Infantil: muitos olhares. São Paulo: Cortez, 1994. p. 107 125.

COUTINHO, Karyne Dias. Lugares de criança - Shopping Centers e o 
disciplinamento dos corpos infantis. 2002. Dissertação de Mestrado em Educação - Universidade Federal do Rio Grande do Sul, Porto Alegre, setembro.

DESCARTES, René, 1596-1650. Discurso do método. São Paulo: Martins Fontes, 1996.

DUCLÓS, Miguel. As meditações cartesianas e o nascimento da subjetividade moderna. Baseado nas anotações de aula da professora Marilena Chauí. http://www.consciencia.org/modera/desmedi.shtml. Acessado em: 01 nov. 2003, às 16h50min.

FOUCAULT, Michel. Vigiar e punir: o nascimento das prisões. Trad. Raquel Ramalhete. 16 ed. Petrópolis, Vozes: 1997.

FORNEIRO, Lina Iglesias. A organização dos espaços na educação infantil. In: ZABALZA, Miguel A. Qualidade em educação infantil. Trad. Beatriz Affonso Neves. Porto Alegre: Artmed, 1998. p. 229-281.

GUATTARI, Félix. As creches e a iniciação. In: Revolução molecular: pulsações políticas do desejo. São Paulo, Brasiliense: 1987.

HALL, Stuart. Identidades culturais na pós-modernidade. Tradução: Tomaz Tadeu da Silva e Guacira Lopes Louro. Rio de Janeiro: DP\&A, 1997.

HARVEY, David. A experiência do espaço e do tempo. In: Condição pósmoderna. 6.ed. São Paulo: Loyola, 1996. p. 185-289.

KANT, Immanuel. Sobre a pedagogia. trad. Francisco Cock Fontanella. Piracicaba: Unimep, 1996.

LARROSA, Jorge. O enigma da infância ou o que vai do impossível ao verdadeiro. In: LAROSSA, Jorge, LARA, Nuria Pérez de (orgs.). Imagens do outro. Petrópolis: Vozes, 1998. p. 67-86.

MINAYO, Maria Cecília de Souza (org.). Pesquisa social: teoria, método e criatividade. $13^{\text {a }}$ ed. Petrópolis:Vozes, 1999.

ROCHA, Eloísa Acires Candal. A pesquisa em educação infantil: trajetória recente de consolidação de uma pedagogia da educação infantil. Florianópolis: 
UFSC. Centro de Ciências da Educação, Núcleo de Publicações, 1999. TONUCCI, Francesco. Com olhos de criança. Porto alegre: Artes Médicas, 1997.

ZABALZA, Miguel A.. Qualidade em educação infantil. Porto Alegre: Artmed, 1998.

\section{Abstract: \\ Discipline of children education? Phisical space and children discipline process.}

This text intents to bring a comprehension about the organization of space in schools, and its influences in child discipline. In this way, the work intents to investigate some relevant aspects about the organization of school space. The research public was a group of children, belonging to an educational institution of Chapecó-SC. Besides this, it was developing an educational action plan (the classes) and the teaching practice happened by supervised stage structure. It was possible to perceive that the space was established according to the modern logic, in other words, fixed places. Also, it was analyzed that those spaces bring some school marks like: desks, blackboard and pedagogical activities to work in class. For sure, these elements show a functional organization, in other words, spaces created by the teacher to indicate place of each class: as the corner of the play, educational activities and reading, collaborating, and in disciplining the child.

Keywords: Children Education. Organization of space. Discipline.

Recebido em agosto 2009.

Aceito em novembro 2009. 